\title{
Underwire bra complicating a gunshot injury
}

\author{
Martha DiGiuseppe, MD • Laura V. Duggan, MD, FRCPC (1)
}

Received: 8 January 2019/Revised: 17 January 2019/ Accepted: 19 January 2019/Published online: 19 February 2019

(c) Canadian Anesthesiologists' Society 2019

\section{To the Editor,}

The velocity, caliber, bullet path, and distance from the weapon can help predict the extent of a gunshot injury. ${ }^{1}$ We present a case where a patient's clothing, specifically her bra's underwire, compounded the trauma inflicted by a firearm.

A 39-yr-old, previously well female (who provided written consent for this report) presented to our level-1 trauma centre having sustained a close-range shotgun injury to her left upper abdomen. Though alert and oriented on first presentation, the patient's respiratory status declined rapidly during her primary trauma survey and she required tracheal intubation. The initial examination and portable chest $x$-ray (performed emergently without full removal of her clothing) revealed a shotgun wound, pellets in her left lower chest and right upper abdomen, tube thoracostomy, and numerous metal artifacts (cell phone, keys, clothing) overlying the chest and abdomen (Figure A). Despite escalating vasopressors and transfusion of four units of packed red blood cells, the patient's hemodynamic status continued to deteriorate (nadir blood pressure, $58 / 36 \mathrm{mmHg}$ ). The patient was brought to the operating room without further imaging for emergent laparotomy.

At laparotomy, copious blood and clots were found. Manual pressure applied by the surgical team to assist with hemostasis revealed the presence of a long curved intra-

\footnotetext{
M. DiGiuseppe, MD · L. V. Duggan, MD, FRCPC ( $\square)$ Department of Anesthesiology, Pharmacology and Therapeutics, University of British Columbia, Vancouver, BC, Canada e-mail: lauravduggan@gmail.com
}

M. DiGiuseppe, MD

e-mail: martha.digiuseppe@alumni.ubc.ca abdominal object with sharp edges. There was initial concern this object may be part of a weapon and hazardous to the patient and operating room staff. After further exposure and team communication, including input from the police officer present in the operating room, it was recognized as being the underwire of the patient's bra (Figure B). We speculate that the underwire had been propelled into her abdominal cavity by the force of the shotgun pellets. The patient's initial portable chest $x$-ray that included multiple overlying artifacts contributed to the initial oversight of the underwire in her right upper quadrant. The metal underwire lacerated the left hemidiaphragm, transected the stomach, and partially transected the left lobe of the liver. Partial liver resection and neartotal gastrectomy were required to control the bleeding. Although she required additional subsequent surgeries, the patient recovered completely.

While the influence of clothing material on the harm caused by bullets is well documented, ${ }^{2-4}$ there is little information regarding the effect of metal components integrated into the clothing itself. With the assistance of a medical librarian, we found only one case report, published fifty years ago, which described perforation of the right ventricle by a bra underwire associated with a ballistic injury. ${ }^{5}$

Our case highlights that clothing, particularly if containing metal objects, may act as additional projectiles in ballistic injuries. Furthermore, overlying metal objects can impair the ability to radiographically identify metal components of clothing that could be contributing to a gunshot injury. Trauma anesthesiologists and all members of the healthcare team may wish to consider the effect of metal objects, such as the bra underwire in this case, in augmenting ballistic injuries. 


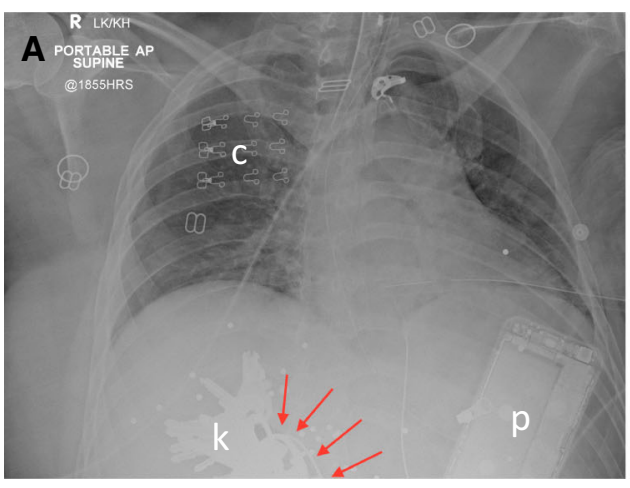

Figure Portable chest radiograph (panel A) showing shotgun pellets in the right upper quadrant of the abdomen along with numerous metal artifacts (including keys [k], a cell phone [p], and bra clasps [c]). After discovering at operation that the metal underwire (panel B)

Conflicts of interest None declared.

Editorial responsibility This submission was handled by Dr. Hilary P. Grocott, Editor-in-Chief, Canadian Journal of Anesthesia.

\section{References}

1. American College of Surgeons. Advanced Trauma Life Support: ATLS. 9th ed. Chicago, IL: American College of Surgeons; 2012.

2. Carr D, Kieser J, Mabbott A, Mott C, Champion S, Girvan E. Damage to apparel layers and underlying tissue due to hand-gun bullets. Int J Legal Med 2014; 128: 83-93.

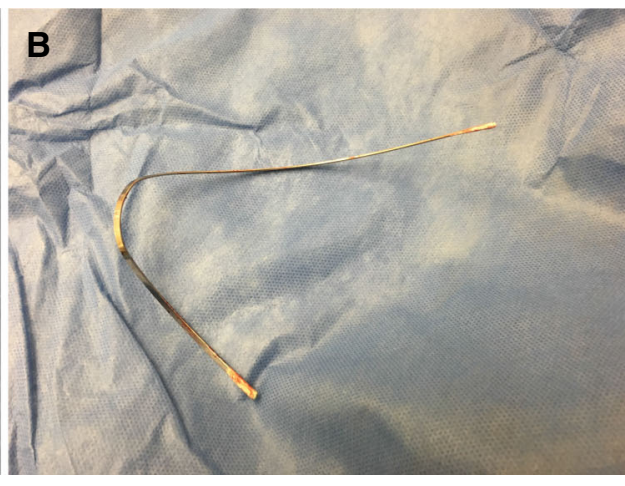

from the patient's bra had injured the liver, stomach, and diaphragm, re-review of the $x$-ray showed that it (red arrows) had been obscured by the other metal artifacts.

3. Kieser DC, Carr DJ, Leclair SC, et al. Clothing increases the risk of indirect ballistic fractures. J Orthop Surg Res 2013; 8: 42.

4. Cail $K$, Klatt E. The effect of intermediate clothing targets on shotgun ballistics. Am J Forensic Med Pathol 2013; 34: 348-51.

5. Mourgue-Molines E, Laurent JC, Rolet JF, Laurent S, Serre L. Intracardiac penetration of a brassiere steel in the course of thoracoabdominal bullet transfixing (French). Ann Chir 1967; 21: 516-20.

Publisher's Note Springer Nature remains neutral with regard to jurisdictional claims in published maps and institutional affiliations. 